\title{
PROCLI DIADOCHI
}

\section{IN PLATONIS CRATYLVM COM M ENTARIA}

\author{
EDIDIT \\ GEORGIVS PASQVALI \\ EDITIO STEREOTYPA \\ EDITIONIS PRIMAE (MCMVIII)
}

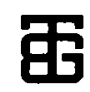

STVTGARDIAE ET LIPSIAE

IN AEDIBVS B.G.TEVBNERI MCMXCIV 
Die Deutsche Bibliothek - CIP-Einheitsaufnahme

Proclus (Diadochus):

[In Platonis Cratylum commentaria]

Procli Diadochi In Platonis Cratylum commentaria / ed. Georgius Pasquali. -

Stutgardiae ; Lipsiae : Teubner, 1994

(Bibliotheca scriptorum Graecorum et Romanorum Teubneriana)

ISBN 3-8154-1731-7

NE: Pasquali, Georg [Hrsg.]

Das Werk einschlieBlich aller seiner Teile ist urheberrechulich geschützt. Jede Verwertung außerhalb der engen Grenzen des Urheberrechtsgesetzes ist ohne Zustimmung des Verlages unzulässig und strafbar. Das gilt besonders für Vervielfältigungen, Übersetzungen,

Mikroverfilmungen und die Einspeicherung und Verarbeitung in elektronischen Systemen.

(C) B. G. Teubner Stuttgart und Leipzig 1994

Printed in Germany

Druck: Druckhaus Köthen GmbH

Buchbinderei: Verlagsbuchbinderei D. Mikolai, Berlin 


\section{MEMORIAE PATRIS}

S. 
